\section{Myths in science}

\section{Andrzej Stasiak}

'Fabulous Science: Fact and Fiction in the History of Scientific Discovery'

by John Waller

Oxford University Press, Oxford, UK

320 pages, $£ 18.99$

ISBN 0192804049

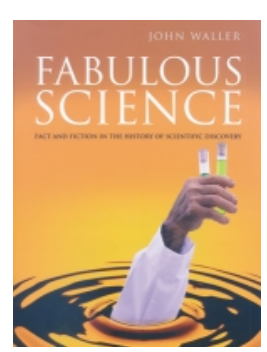

We all like stories that feature a positive hero fighting evil or ignorance, with whom we can easily identify or hold up as a good example to a younger generation. We may even be tempted to 'improve' a story for greater impact to make the hero more positive and outstanding, especially when the person concerned is someone as special as ourselves. Indeed, we scientists are not much different to others, so it should come as no surprise that many popular science stories have been frequently 'ameliorated', either by journalists and biography authors who simply wanted to tell a fascinating account, or by direct participants who wished to improve their image and highlight their own contribution. And multiple rephrasing of this 'improved' story in sequential editions of books and science dictionaries causes the myth to become reality. As scientists, however, in addition to a good story, we also like to know the truth, especially if it concerns science itself. Enter the historians of science. In his book Fabulous Science: Fact and Fiction in the History of Scientific Discovery, John Waller, a research fellow at the Wellcome Trust Centre for the History of Medicine, uncovers the real stories behind several famous scientists and scientific events. In so doing, the unravelling of these scientific myths produces interesting stories in themselves, although obviously, their starring heroes are not portrayed quite so positively. While reading this book, it is a surprise to discover that widely accepted important scientific events are in fact mere myths in each case Waller dissects.

Let me illustrate this using one example from the book. Many people know that the theory of general relativity proposed by Albert Einstein in 1915, which postulated that large gravitational fields warp the space-time continuum, was met with scepticism until 1919, when a solar eclipse provided an opportunity to observe directly the bending of starlight passing near the sun. This nice story helps everyone to accept the general theory of relativity without a need to understand it, as almost everyone believes that the predicted effect is clearly visible and easily demonstrable. For those who want to know the truth, Waller recounts the hidden details of Arthur Eddington's astronomical expedition to photograph the eclipse and measure the space-time warping. Eddington was an early convert to the general relativity theory, and greatly wished to provide the definitive proof through his own astronomical observations. Despite the ongoing First World War and the difficult economic situation, he departed from Britain as the head of a two-part expedition to remote places in Africa and South America. The snag was that the effect to be measured required a precision that could not be provided by the mobile astronomical equipment available at that time. Inclement weather and other problems further limited the number of usable images-eventually only about 30 photos were taken of the eclipse. While analysing the data on his return, Eddington promptly rejected 19 of these photos because they supported the old Newtonian view of the world. The analysis of the remaining images was carried out in such a way that the highest statistical weight was not given to those that were technically the best, but to those that gave the results closest to the one desired by Eddington. It is therefore not surprising that the final outcome of his data analysis entirely confirmed Einstein's predictions. Eddington used the Royal Society forum on 6 November 1919, together with the endorsement of its president, to declare the experimental confirmation of Einstein's theory of general relativity. The following day, the banner headline in the British newspaper The Times declared: Revolution in Science, New Theory of the Universe, Newtonian Ideas Overthrown. Yes, this was the day of the revolution in the educated view of the world, but the material proof for this revolution was still lacking. Eddington was knighted in 1930, and his experimental, or rather visionary, verification of the general theory of relativity contributed greatly to his selection for this honour. The myth of the romantic eclipse story persists today and is exaggerated even further, as exemplified by Stephen Hawking's recent book The Universe in a Nutshell, where the perceived displacement of the eclipsed star is drawn as large as half of the solar disc! The myth persisted despite the fact that a much better equipped British astronomical expedition, trying to repeat Eddington's measurements in 1962, declared, after a lot of frustrating effort, that the method was unreliable and could not be implemented successfully.

Waller presents 13 mythical stories in total, starring such scientific icons as Louis Pasteur, Gregor Mendel, Charles Darwin and Alexander Fleming. In most cases, the scientists that were directly involved are shown to manipulate reality to edify their own myths. In the other, maybe more interesting, cases, the myth was created without the participant's intervention. Each story is well researched and the bibliographic sources are listed and correctly credited. For me, each plot was completely unexpected, illuminative and interesting. Waller's CV includes a Masters in human biology, and this explains his proficiency in the complex subjects of biology and medicine. I highly recommend this book to anyone interested in the history and social structure of science.

\section{Andrzej Stasiak is at the University of} Lausanne, Switzerland.

E-mail:Andrzej.Stasiak@lau.unil.ch

doi:10.1038/sj.embor.embor779 